\title{
МОЛОДЕЖЬ И ОБЩЕСТВО: УРОКИ ИСТОРИИ. К 80-ЛЕТИЮ ПРОФЕССОРА Б. А. РУЧКИНА
}

\author{
А. Б. Ручкин \\ (Центр образования и культуры «ГРИНТ», г. Москва)
}

Аннотация: В статье представлен обзор научной сессии, посвященной 80-летию Б. А. Ручкина (09.01.1936-02.06.2015), которая состоялась 1 марта 2015 г. в Московском гуманитарном университете.

Ключевые слова: молодежь; общество; Московский гуманитарный университет; Борис Александрович Ручкин; обзор

\section{YOUTH AND SOCIETY: 80TH ANNIVERSARY OF PROFESSOR B.A. RUCHKIN}

\author{
A. B. Ruchkin
}

(GRINT Centre for Education and Culture)

Abstract: This is a summary of a scientific session dedicated to the 80th anniversary of B. A. Ruchkin (09.01.1936-02.06.2015), which took place on March 1, 2016 at Moscow University for the Humanities.

Keywords: youth; society; Moscow University for the Humanities; B.A. Ruchkin; summary article

1 марта 2015 г. в Институте фундаментальных и прикладных исследований Московского гуманитарного университета состоялась научная сессия «Молодежь и общество: уроки истории», посвященная 80-летию профессора Бориса Александровича Ручкина (9.01.1936-2.06.2015).

С приветственным словом выступил директор Института фундаментальных и прикладных исследований МосГУ, доктор философских наук, профессор, заслуженный деятель науки Российской Федерации,вицепрезидент Международной академии наук (IAS) B. А. Луков. Он осветил наиболее важные этапы и направления профессиональной деятельности Б. А. Ручкина (положение молодежи в обществе, правдивое освещения советского периода российской истории, место и роль комсомола в советском обществе), охарактеризовав его как видного организатора образования и науки, ученого-историка и руководителя и участника крупных научных проектов по изучению проблем молодежи, молодежного движе- 


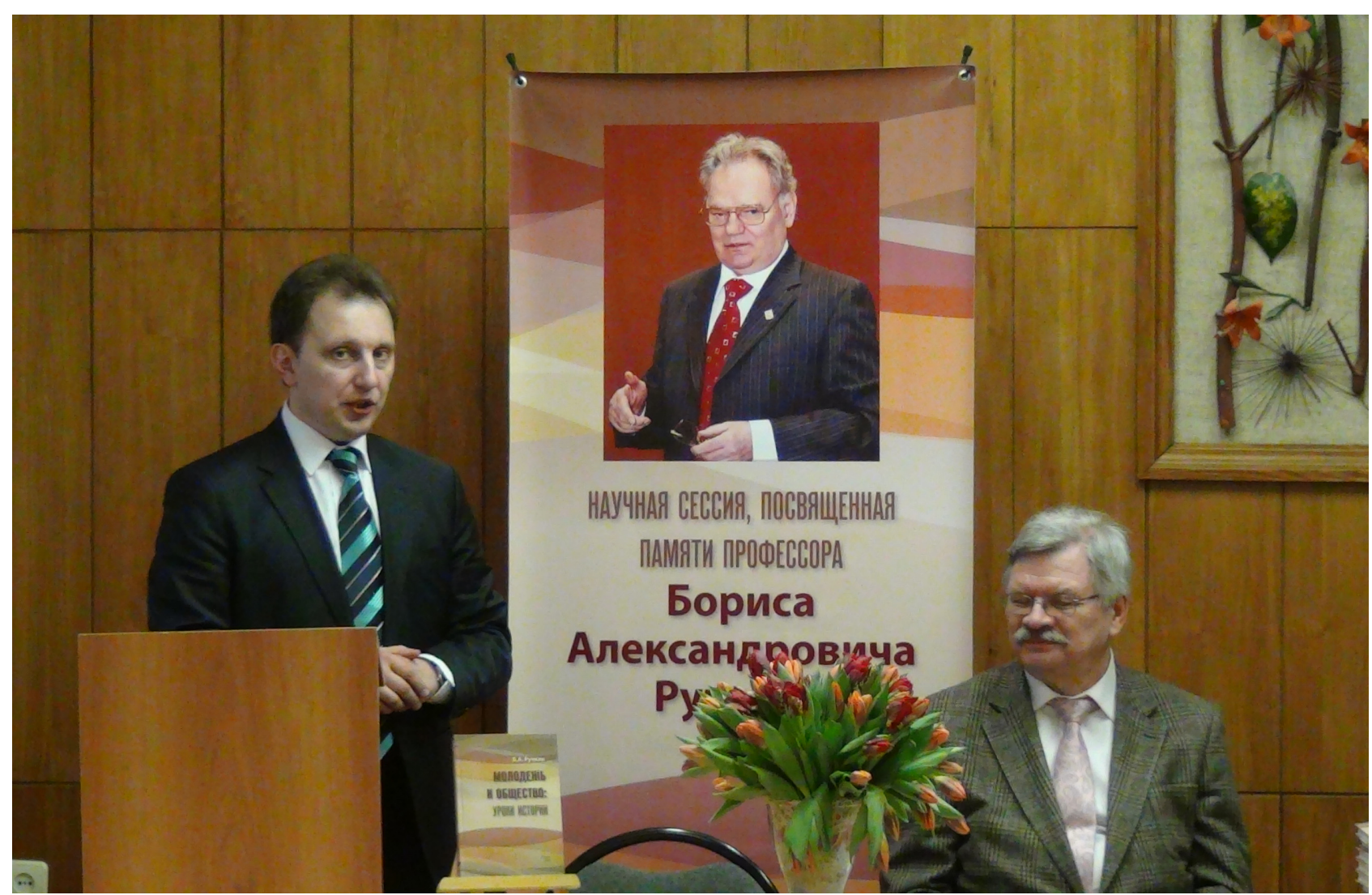

ния в СССР.

Говоря о деятельности Б. А. Ручкина в качестве директора Центра исторических исследований ИФПИ МосГУ (2008-2015 гг.), Вал. А. Луков напомнил о том, что Борис Александрович стал одним из организаторов общеуниверситетского проекта по «демифологизации истории России», призванного стать визитной карточкой вуза в научном и образовательном сообществе и соединить научные силы историков, социологов, политологов, культурологов, экономистов, правоведов, психологов, педагогов, филологов, представителей других направлений науки, которые развиваются в МосГУ. Особо была отмечена гражданская позиция Б. А. Ручкина, проявившаяся в дискуссиях о новом учебнике истории, который он рассматривал как важный ориентир государственной идеологии.

Далее Вал. А. Луков представил присутствующих на круглом столе преподавателей и выпускников бывшей Высшей комсомольской школы, хорошо знавших Б. А. Ручкина с рубежа 1970-х и 1980-х годов. Выпускник ВКШ 1974 г., доктор философских наук, профессор, ректор Национального института бизнеса, С. И. Плаксий посвятил свое выступление обзору многолетней научно-педагогической деятельности Б. А. Ручкина, начиная с преподавания научно-практических дисциплин первым слушателям ВКШ и заканчивая разработкой и апробацией инновационных вузовских образовательных стандартов. С. И. Плаксий особо выделил деятельность Б. А. Ручкина в качестве проректора по научной и учебной работе МосГУ (1994-2008 гг.) на этапе становления этого негосударственного вуза, его 
вклад в организацию учебного и научного процесса.

Заслуженный деятель науки РФ, доктор исторических наук, профессор, профессор кафедры истории Московского гуманитарного университета А. А. Королев уделил особое внимание периоду создания и становления в ВКШ кафедры комсомольского строительства, где в начале 1970-х гг. на основе практики управления комсомольскими организациями специалистами различных областей гуманитарного знания, под руководством Б. А. Ручкина был разработан и успешно внедрен учебный курс «Комсомольское строительство», как подчеркнул А. А. Королев, не имевший тогда аналогов ни в социалистических, тем более в капиталистических странах. Профессор А. А. Королев подчеркнул, что тесная связь Б. А. Ручкина с практикой комсомольской работы, его интерес к изучению реальных общественных проблем, активное участие в проведении социологических исследований делали его лекции и выступления яркими, информативными и запоминающимися.

Выступление В. И. Муконина (в 1970-х гг. возглавлявшего комсомольскую организацию в столице БАМа г. Тынде) было посвящено одной из интересных страниц научной деятельности Б. А. Ручкина, связанных с проведением социологических исследований молодежи на строительстве в том числе и самых удаленных объектов Байкало-Амурской магистрали. Проведение комплексного исследования позволило собрать уникальный материал о положении, настроении, ценностных ориентирах советской молодежи, который лег в основу многочисленных публикаций. В личных архивах до сих пор хранятся уникальные материалы, связанные с историей освоения Сибири и Дальнего Востока. После своего выступления В. И. Муконин передал руководству ИФПИ МосГУ уникальные материалы по социально-экономической истории Тюменского региона и БАМа, относящиеся к 1970-1980-м гг., с пожеланиями их активного использования, включения в научный оборот и продолжения научной деятельности по изучению молодежи.

Выпускник ВКШ, декан факультета рекламы МосГУ, доктор исторических наук, профессор А. Д. Бородай рассмотрел научно-педагогическую деятельность Б. А. Ручкина в широком общественно-политическом контексте становления и развития вуза, обобщил опыт формирования саратовского научного землячества, традиций взаимной поддержки и открытого сотрудничества в научной жизни. Отдельное внимание было уделено деятельности диссертационного совета МосГУ, в работе которого Б. А. Ручкин принимал активное участие.

О совместных проектах и опыте взаимодействия с Центром исторических исследований ИФПИ МосГУ говорил в своем выступлении заместитель директора Орловского филиала РАНХиГС, доктор исторических 
наук, профессор В. А. Ливцов. Особо отмечалось роль Б. А. Ручкина в проведении научных мероприятий, посвященных реализации молодежной политики, концептуальной разработке ее регионального компонента и определении роли вузов в ее реализации.

Об актуальности опыта создания курсов, построенных на основе творческой обработки практических знаний, важности ознакомления с накопленным предшествующими поколениями опытом научного поиска и инновационной деятельности говорил в своем выступлении А. А. Ручкин, студент исторического факультета МГУ им. М. В. Ломоносова, молодой преподаватель Школы педагогического мастерства, продолжатель династии историков.

Профессор кафедры истории МосГУ Н. Д. Оконова поблагодарила руководство ИФПИ МосГУ за возможность проведения сессии, приуроченной к 80-летию Б. А. Ручкина, в стенах, где прошли 45 лет его трудовой жизни, выразила признательность участникам встречи за информативные выступления, охватившие все этапы научно-педагогической деятельности.

В завершение сессии, продолжавшейся почти 3 часа, состоялась презентация сборника «Молодежь и общество:уроки истории» (Москва, 2016). Представляя юбилейный сборник научных трудов Б. А. Ручкина «Молодежь и общество: уроки истории» (Ручкин, 2016) Вал. А. Луков отметил, что это издание не только демонстрирует вклад автора в науку, но и дает представление о личности юбиляра - о его мировоззрении, понимании Происходящего, научных интересах, авторском стиле, содержит штрихи к его портрету как человека своей эпохи, своей страны, своего народа.

Подводя итоги научной сессии, директор Центра образования и культуры «Гринт», доктор исторических наук А. Б. Ручкин выразил искреннюю признательность общественному и научному оргкомитетам встречи и выразил надежду, что материалы выступлений, в том числе поступившие из Архангельска, Оренбурга, Саратова, получат отражение во втором томе издания «Молодежь и общество: уроки истории», издание которого запланировано на май 2016 г.

\section{СПИСОК ЛИТЕРАТУРЫ}

Ручкин, Б. А. (2016) Молодежь и общество: уроки истории: сб. науч. трудов / сост. А. Б. Ручкин. М. : Центр «ГРИНТ». 226 с. 
Ручкин Александр Борисович - доктор исторических наук, директор Центра образования и культуры «ГРИНТ».Адрес: 111395, Россия, г. Москва, ул. Юности, д. 5, корп. 6. Тел.: +7 (499) 374-74-30. Эл. адрес: arouchkin@ yandex.ru

Ruchkin Aleksandr Borisovich, Doctor of History, Director, GRINT Centre for Education and Culture. Address: Bldg.6, 5 Yunosti St., Moscow, Russian Federation. Tel.: +7 (499) 374-74-30. E-mail: arouchkin@yandex.ru 